Marquette University

e-Publications@Marquette

Psychology Faculty Research and Publications

Psychology, Department of

6-1-2015

Executive Functioning and Risk for Alzheimer's

Disease in The Cognitively Intact: Family History Predicts Wisconsin Card Sorting Test Performance

Kathleen Hazlett

Marquette University, kathleen.hazlett@marquette.edu

Christina Marie Figueroa

Marquette University

Kristy A. Nielson

Marquette University, kristy.nielson@marquette.edu

Accepted version. Neuropsychology, Vol 29, No. 4 (June 2015): 582-591. DOI. @ 2015 American Psychological Association. Used with permission.

This article may not exactly replicate the final version published in the APA journal. It is not the copy of record. 


\title{
Executive Functioning and Risk for Alzheimer's Disease in The Cognitively Intact: Family History Predicts Wisconsin Card Sorting Test Performance
}

\author{
Kathleen E. Hazlett \\ Department of Psychology, Marquette University \\ Milwaukee, WI \\ Christina M. Figueroa \\ Department of Psychology, Marquette University \\ Milwaukee, WI \\ Kristy A. Nielson \\ Department of Psychology, Marquette University \\ Department of Neurology, Medical College of Wisconsin \\ Milwaukee, WI
}

Objective: Alzheimer's disease (AD) research typically focuses on memory. However, executive functioning (EF) deficits are also common among AD patients; these deficits are associated with decreased functioning in activities of daily living, an important criterion in diagnosing AD. A classic test of EF ability, the Wisconsin Card Sort Test (WCST), has demonstrated sensitivity to differentiating individuals with $A D$ from healthy controls, discriminating $A D$ 
groups based on disease severity, and distinguishing AD from other types of dementia. Such sensitivity to AD raises the possibility that the WCST is also sensitive to very early, preclinical differences between those who have heightened risk for AD and those with lower risks. Method: The current study, therefore, examined WCST performance in healthy, cognitively intact older adults with a first-degree (i.e., sibling or parent) family history (FH) of AD $\left(n_{-} 18\right)$ and those with no such FH of AD $\left(n_{-} 24\right)$. Results: Results revealed significant group differences for Categories Achieved, Percent Conceptual Level Responses, Total Errors, Perseverative Errors, and NonPerseverative Errors, with the $\mathrm{FH}_{-}$group consistently exhibiting poorer performance. Moreover, hierarchical regression analyses indicated that after accounting for age, sex, and education, $\mathrm{FH}$ significantly predicted all 5 of these variables. Conclusions: These results speak to the potential role of EF in bolstering the current understanding of early cognitive markers of future decline. Furthering what is known about the relationship between AD and nonmemory specific domains of cognition such as executive functioning may allow for better prediction of cognitive decline and potential progression to AD.

Keywords: Alzheimer's disease, executive function, genetic predisposition to disease, neuropsychological tests, risk factors, predictive value of tests

Early detection of Alzheimer's disease (AD) will be essential for the development and implementation of interventions that can prevent its damaging effects from progressing to produce significant or devastating impairments to quality of life. In the current era of increasing life expectancy, a growing aged population, and heightened AD prevalence (Alzheimer's Association, 2012; 2013), identification of early markers of future decline is indeed urgent. As memory impairment is a hallmark symptom of AD (Clark et al., 2012; Salmon \& Bondi, 2009) and deficits in this area are particularly devastating to independence and quality of life (Andersen, Wittrup-Jensen, Lolk, Andersen, \& Kragh-Sørensen, 2004), AD research has been primarily focused on it. However, memory is not the only cognitive domain to show early decline in individuals who will go on to be diagnosed with AD. As such, examining performance in domains of cognitive functioning beyond memory may provide additional insight into the differentiation between these groups and improve the potential for early detection of AD.

Executive functioning (EF) is one such cognitive domain that has recently received growing attention in the AD literature (Duarte et al., 2006; Espinosa et al., 2009; McGuinness, Barrett, Craig, Lawson, \& Passmore, 2010). Indeed, recent diagnostic recommendations from 
the National Institute on Aging and the Alzheimer's Association include a specific classification for nonamnestic AD presentations characterized specifically by executive dysfunction (McKhann et al., 2011). EF is an umbrella term used to describe higher order cognitive processes that are critical for engagement in complex thought and behavior (Daniels, Toth, \& Jacoby, 2006; Elliott, 2003). It includes abilities such as planning, shifting from one mental "set" to another, updating and monitoring of information, and inhibitory control (Miyake et al., 2000). EF deficits among individuals who have been diagnosed with AD are now widely recognized (Espinosa et al., 2009; Stokholm, Vogel, Gade, \& Waldemar, 2006; Takeda et al., 2010). More important, it has been suggested that memory deficits in AD are related to executive impairments (Baudic et al., 2006; Gleichgerrcht, Torralva, Martinez, Roca, \& Manes, 2011; Hasher, Lustig, \& Zacks, 2007) and that EF deficits are associated with decreased functioning in activities of daily living, which represent an essential criterion in the diagnosis of AD (Jefferson, Paul, Ozonoff, \& Cohen, 2006; Martyr \& Clare, 2012). Research indicating that AD pathophysiology begins years, and possibly even decades, before the onset of clinical symptoms has spurred the exploration of preclinical markers of future cognitive decline (Sperling et al., 2011). However, only very limited work has been conducted to assess EF abilities in individuals at this early, preclinical stage. One promising recent finding suggested that EF was sensitive to subtle differences between cognitively intact elders who differ by family history $(\mathrm{FH})$ of $A D$ when power was increased by examining multiple tests collectively (e.g., verbal fluency, Trail-making and Stroop; Donix et al., 2012).

One classic and robust test of EF is the Wisconsin Card Sorting Test (WCST). Examinees are asked to individually match test cards to one of four possible key cards depicting various shapes and colors (Grant \& Berg, 1948; Heaton, 1981; Heaton, Chelune, Talley, Kay, \& Curtis, 1993). The correct sorting principle is never explicitly stated and is changed without warning several times during the test after the participant makes multiple consecutively correct matches (i.e., after each category is achieved). The examinee is expected to use experimenter feedback (i.e., correct or incorrect) to deduce the sorting principle and to shift strategy to learn each new rule. 
When it was first introduced as a neuropsychological testing instrument, use of the WCST focused primarily on the assessment of frontal lobe lesions, which resulted in poor EF test performance (Miyake et al., 2000). Specifically, frontal lobe lesions are linked to decreased response inhibition and subsequent difficulty shifting to a new sorting principle on the WCST, a concept that has been termed perseveration (Eling, Derckx, \& Maes, 2008). In addition to perseveration, the WCST measures abstract reasoning by tapping into the ability to deduce the correct matching principles throughout the test (despite the lack of concrete instructions), as well as the ability to shift cognitive strategies when the matching principle suddenly changes (Heaton et al., 1993). More important, as understanding of the construct of EF has improved, the WCST has become much more broadly used to evaluate EF and frontal lobe functioning in healthy brains and in various disorders, including AD (Eling et al., 2008).

Evidence suggests that the WCST is sensitive to AD, differentiating individuals with $A D$ from healthy controls, discriminating between $A D$ groups based on disease severity, and distinguishing $A D$ from other types of dementia. Specifically, greater perseveration is apparent in those with $A D$ and mild cognitive impairment (often viewed as prodromal AD) than in healthy controls (Bondi, Monsch, Butters, Salmon, \& Paulsen, 1993; Nagahama et al., 2003); and those at later, more severe stages of AD achieve fewer WCST categories than those at milder stages of the disease (Bondi et al., 1993). Finally, the number of Categories achieved, Unique Errors, and Total Errors can differentiate individuals with $A D$, vascular dementia, and healthy controls from each other (Chao, Hao, Chao, Shi, \& Chao, 2013). Notably, these studies have typically used a modified WCST (Nelson, 1976) that is shorter and less complex than the traditional test, such as including only test cards that can be matched based on one sorting principle (e.g., Nagahama et al., 2003; Nelson, 1976; Takeda et al., 2010). This approach is often used because the degree of impairment in these populations otherwise leads to frequent inability or refusal to complete the test.

Given the sensitivity of at least the simplified versions of the WCST to AD, examining performance among cognitively intact individuals who are at risk for $A D$ could provide valuable insight into preclinical cognitive changes and potential markers for future cognitive

Neuropsychology, Vol 29, No. 4 (June 2015): pg. 582-591. DOI. This article is (C American Psychological Association and permission has been granted for this version to appear in e-Publications@Marquette. American Psychological Association does not grant permission for this article to be further copied/distributed or hosted elsewhere without the express permission from American Psychological Association. 
decline. Second only to advancing age, having a relative with $A D$ (particularly a first-degree relative such as one or both parents) is the most significant risk factor for developing $A D$ (e.g., Mosconi et al., 2010; Silverman et al., 1994). A number of cognitive and neural differences between cognitively intact individuals with a FH of AD and those without such history have been described (cf. Mosconi et al., 2010), which strongly suggests a genetic basis as at least a prominent route of transmission of AD. Although studies assessing $\mathrm{FH}$ alone cannot speak to the specific underlying genetic mechanisms, $\mathrm{FH}$ is a cost-effective and noninvasive method to assess risk for AD that can examine potential early markers for $A D$ in intact elders, possibly including EF. It is currently unknown whether the WCST, either modified or traditional form, would be sensitive to early or subtle effects of AD risk on executive functioning. Given a cognitively intact sample, it was deemed most appropriate to retain the complexity of the traditional WCST toward capturing early, subtle differences in performance that might be revealed by $\mathrm{FH}$. To this end, the present study examined performances on the traditional WCST in cognitively intact older adults with a FH of AD and compared them with the performances of comparable elders with no AD FH. We predicted that a positive $\mathrm{FH}$ of $\mathrm{AD}$ would be associated with poorer performance.

\section{Method}

\section{Participants and Procedure}

Forty-two older adults participated in the present study (see Table 1). All protocols were approved by the local Institutional Review Board and participants received compensation. They were recruited from the local community via newspaper advertisements that highlighted recruiting healthy participants with a family member diagnosed with $A D$. Family history was defined by presence $\left(\mathrm{FH}^{+}\right)$or absence $\left(\mathrm{FH}^{-}\right)$of a first degree relative (i.e., parent or sibling) with diagnosed $A D$; autopsy confirmation of diagnosis was not required. Eighteen participants had first degree FH of AD: 2 with both maternal and paternal, 9 maternal only, 5 paternal only, and 2 by siblings ( 1 with a twin sister, and 1 with both a brother and a sister). The FH survey was collected during the first session but not tabulated by the examiner until after testing was concluded; thus, it was not a 
determinant for or a condition of study inclusion and $\mathrm{FH}$ status was not explicitly known by the examiner during testing. All participants were in good general health with few reports of chronic, acute, or past health conditions or smoking $(n=3)$ and no reports of substance abuse. The only notable chronic condition was high blood pressure: $48 \%$ of the sample $(n=20)$ reported being treated for blood pressure control $\left(54 \%\right.$ of $\mathrm{FH}^{-} ; 39 \%$ of $\left.\mathrm{FH}^{+}\right)$. No health conditions varied significantly in frequency between $\mathrm{FH}$ groups (all $\mathrm{X}^{2}, p>.35$ ).

Table 1

Descriptive Statistics (Mean (SD)) for Demographic and Screening Tests by AD Family History Group

\begin{tabular}{lcccc}
\hline & & & & \\
& All & \multicolumn{1}{c}{$\mathrm{FH}^{-}$} & $\mathrm{FH}^{+}$ & $\begin{array}{c}\text { Between- } \\
\text { groups } p\end{array}$ \\
\hline$n$ & 42 & 24 & 18 & \\
Age (years) & $67.89(9.79)$ & $69.23(10.67)$ & $66.11(8.42)$ & 0.31 \\
Education (years) & $15.25(2.43)$ & $14.88(1.94)$ & $15.75(2.94)$ & 0.25 \\
Sex & Female $=28$ & Female $=18$ & Female $=10$ & $0.21^{\text {a }}$ \\
& Male $=14$ & Male $=6$ & Male $=8$ & \\
MMSE & $28.93(1.22)$ & $28.75(1.39)$ & $29.17(0.92)$ & 0.28 \\
SKT & $33.81(3.80)$ & $34.35(2.74)$ & $33.11(4.83)$ & 0.34 \\
BDI & $4.67(4.16)$ & $5.29(4.63)$ & $3.83(3.38)$ & 0.27 \\
BAI & $2.36(2.52)$ & $2.83(2.88)$ & $1.72(1.81)$ & 0.16 \\
\hline
\end{tabular}

Note. $\mathrm{FH}=$ family history of $\mathrm{AD} ; \mathrm{MMSE}=$ Mini Mental State Exam raw score (out of 30 ); SKT $=$ Synonym Knowledge Test raw score (out of $40)$; $\mathrm{BDI}=$ Beck Depression Inventory-II raw score $(0-63$ possible, all participants $0-19$, median $=3.00$ ); BAI $=$ Beck Anxiety Inventory raw score $(0-63$ possible, all participants $0-12$, median $=2.00)$.

${ }^{a} \chi^{2}$ test (all others based on independent $t$ tests).

\section{Materials and Procedure}

Informed consent was obtained from all participants at the start of the testing session. Participants then completed several neuropsychological tests and surveys, only a subset of which was examined for the present study.

\section{Mini-Mental State Examination (MMSE)}

The MMSE (Folstein, Folstein, \& McHugh, 1975) was administered to screen for global cognitive functioning. This measure provides indices of orientation to time and place, word registration, attention and calculation, word recall, naming, repetition, comprehension, reading, writing, and drawing. All participants were

Neuropsychology, Vol 29, No. 4 (June 2015): pg. 582-591. DOI. This article is (C) American Psychological Association and permission has been granted for this version to appear in e-Publications@Marquette. American Psychological Association does not grant permission for this article to be further copied/distributed or hosted elsewhere without the express permission from American Psychological Association. 
required to score at least 24 out of 30 to be included in the larger study from which these data were taken; this criterion is consistent with classic cutoffs for intact cognitive performance (Tombaugh \& McIntyre, 1992). Recent research has also emphasized the use of 27 as a cut-off score to improve sensitivity and specificity in highly educated White examinees (e.g., O'Bryant et al., 2008), which also characterizes our sample. Only four participants in the present study scored below 27. Each of these four scored 26, which was due principally to poor performance on the Serial $7 \mathrm{~s}$ Attention item (4 points lost on Serial 7s, $n=2$; 3 points lost on Serial 7s, $n=1$; and 2 points lost on Serial $7 \mathrm{~s}, n=1$ ).

\section{Synonym Knowledge Test (SKT)}

The SKT is a computerized version of the Shipley Institute of Living Scale Vocabulary subtest (Langenecker, Zubieta, Young, Akil, \& Nielson, 2007; Shipley, 1946), which was administered to estimate verbal intelligence. On each of 40 trials, participants indicated via keyboard press which word out of the four answer options best matched the meaning of a target word presented at the top of the screen. One participant in the $\mathrm{FH}^{-}$group did not complete this test because of technical difficulties.

\section{Beck Depression Inventory-II (BDI-II)}

The BDI-II (Beck, Steer, \& Brown, 1996) is a 21-item self-report instrument assessing depressive symptoms. Participants in the present study had scores within the minimal range $(0-13=$ minimal) except one $\mathrm{FH}^{-}$participant who fell in the mild range at $19(14-19=$ mild $)$.

\section{Beck Anxiety Inventory (BAI)}

The BAI (Beck \& Steer, 1993) is a 21 -item self-report instrument assessing common symptoms of anxiety. Participants in the present study had scores between 0 and 7 , which were within the minimal range $\left(0-7=\right.$ minimal) except one $\mathrm{FH}^{-}$participant who fell in the mild range at $12(8-15=$ mild $)$. 
NOT THE PUBLISHED VERSION; this is the author's final, peer-reviewed manuscript. The published version may be accessed by following the link in the citation at the bottom of the page.

\section{Wisconsin Card Sorting Test (WCST)}

The WCST (Grant \& Berg, 1948; Heaton, 1981; Heaton et al., 1993 ) is classic test of executive functioning. Participants were provided two decks of cards and asked to match each card, one at a time, to one of four key cards, after which they received feedback from the experimenter (i.e., correct or incorrect). Test cards can be matched to the key cards based on "color" (red, green, blue, or yellow), "form" (triangle, star, cross, or circle), and/or "number" (1, 2, 3 , or 4 shapes on the card), with some cards matching the key cards based on multiple sorting principles (i.e., a test card depicting two green circles would match a key card depicting two green triangles based on both the number and color principles). However, only one of these sorting principles is correct at any given time and the correct sorting principle changes each time the participant achieves 10 consecutive correct responses (i.e., one completed category). The correct sorting principle is initially unknown to the participant and is never explicitly stated by the examiner during the test. The participant is told that the experimenter cannot tell him or her how to match the cards, but will indicate after each trial whether the participant's card placement was correct or incorrect. Participants are expected to utilize this feedback to learn the correct sorting principle to accurately advance through the test.

Herein, participants matched each of the cards until they had correctly completed six categories or placed all 128 cards, whichever came first. The following metrics were examined in the present study: Categories Achieved (number of sets of 10 consecutive correct responses completed out of six possible), Trials to Complete First Category (number of trials completed before obtaining the first set of 10 consecutive correct responses), Failure to Maintain Set (number of times the set was lost after five or more consecutive correct responses), Percent Conceptual Level Responses (percent of all completed trials in which there were three or more consecutive correct responses), Total Errors (total number of incorrect trials), Perseverative Errors (total number of errors involving preservation to the previously established sorting principle), and Non-Perseverative Errors (total number of errors that did not involve preservation).

Neuropsychology, Vol 29, No. 4 (June 2015): pg. 582-591. DOI. This article is (C American Psychological Association and permission has been granted for this version to appear in e-Publications@Marquette. American Psychological Association does not grant permission for this article to be further copied/distributed or hosted elsewhere without the express permission from American Psychological Association. 
NOT THE PUBLISHED VERSION; this is the author's final, peer-reviewed manuscript. The published version may be accessed by following the link in the citation at the bottom of the page.

\section{Results}

Table 1 presents the demographic and descriptive statistics on the sample. There were no significant differences between the $\mathrm{FH}^{-}$and $\mathrm{FH}^{+}$groups based on age, sex, or years of education. Furthermore, these groups did not differ significantly on screening tests of depression (BDI-II) or anxiety (BAI). Only four participants in the sample reported taking antidepressant medications; three in the $\mathrm{FH}^{-}$ group, one in the $\mathrm{FH}^{+}$group. The groups were also comparable in global cognitive functioning (MMSE) and vocabulary (SKT). All participants scored within normal limits on the MMSE (16 participants [8 in each $\mathrm{FH}$ group $]=$ score of $30 ; 16$ participants $\left[10 \mathrm{FH}^{-}, 6 \mathrm{FH}^{+}\right]=$ $29 ; 5$ participants $\left[2 \mathrm{FH}^{-}, 3 \mathrm{FH}^{+}\right]=28 ; 1$ participant $\left[\mathrm{FH}^{+}\right]=27 ; 4$ participants [all $\left.\mathrm{FH}^{-}\right]=26$ ). Scores on the SKT were above average for the general population, as would be expected in this age and educational range (cf., Creed \& Wiener, 1999).

To examine whether any demographic variables contributed to performance on the WCST, exploratory correlations were performed between the demographic variables, basic cognitive functioning indices, and the WSCT performance variables. These are presented in Table 2. Education did not differ between groups and was not correlated with any study variables except Failure to Maintain Set, only in the $\mathrm{FH}^{+}$group. However, age and sex were correlated with the WCST in multiple comparisons. Specifically, greater age was associated with poorer performance in the overall sample, which was driven by significant correlations with several test metrics specifically in the $\mathrm{FH}^{+}$group. Sex was significantly correlated with some of the same metrics, but only in the $\mathrm{FH}^{-}$group, such that being male was associated with poorer performance. General cognitive functioning (MMSE, SKT) did not significantly correlate with WCST indices except in the $\mathrm{FH}^{-}$group, where a greater number of Categories Achieved was associated with higher SKT performance.

Neuropsychology, Vol 29, No. 4 (June 2015): pg. 582-591. DOI. This article is (C) American Psychological Association and permission has been granted for this version to appear in e-Publications@Marquette. American Psychological Association does not grant permission for this article to be further copied/distributed or hosted elsewhere without the express permission from American Psychological Association. 
NOT THE PUBLISHED VERSION; this is the author's final, peer-reviewed manuscript. The published version may be accessed by following the link in the citation at the bottom of the page.

Table 2

Correlations Amongst Study Variables

\begin{tabular}{|c|c|c|c|c|c|c|c|c|c|c|c|}
\hline & Sex & Edu & MMSE & SKT & WCST-CA & WCST-TCFC & WCST-FMS & WCST-PCLR & WCST-TE & WCST-PE & WCST-NPE \\
\hline \multicolumn{12}{|l|}{ Age } \\
\hline All & -.02 & .20 & $-.32^{*}$ & -.25 & -.27 & .22 & -.04 & $-.32^{*}$ & $.35^{\circ}$ & $.39^{* *}$ & .16 \\
\hline $\mathrm{FH}^{-}$ & -.10 & .29 & -.37 & $-.51^{*}$ & -.18 & .02 & -.08 & -.21 & .23 & .27 & .17 \\
\hline $\mathrm{FH}^{+}$ & .00 & .19 & -.12 & -.10 & $-.66^{* *}$ & $.51^{\circ}$ & .07 & $-.74^{* *}$ & $.77^{* *}$ & $.79^{* *}$ & .34 \\
\hline \multicolumn{12}{|l|}{ Sex } \\
\hline All & - & -.10 & -.21 & .25 & .16 & $-.31^{*}$ & -.11 & .19 & -.18 & -.16 & -.15 \\
\hline $\mathrm{FH}^{-}$ & - & -.04 & -.25 & .15 & $.51^{\circ}$ & -.36 & -.25 & $.48^{\circ}$ & $-.44^{*}$ & $-.51^{*}$ & -.32 \\
\hline $\mathrm{FH}^{+}$ & - & -.08 & -.08 & .28 & -.08 & -.27 & -.11 & -.11 & .12 & .10 & .11 \\
\hline \multicolumn{12}{|l|}{ Edu } \\
\hline All & & - & .23 & .18 & .05 & -.07 & -.22 & .05 & -.03 & .06 & -.18 \\
\hline $\mathrm{FH}^{-}$ & & - & .12 & .29 & .26 & -.36 & -.14 & .21 & -.25 & -.23 & -.20 \\
\hline $\mathrm{FH}^{+}$ & & - & .36 & .20 & .14 & -.03 & $-.47^{*}$ & .11 & -.06 & .07 & -.30 \\
\hline \multicolumn{12}{|l|}{ MMSE } \\
\hline All & & & - & .15 & -.06 & .05 & .00 & .00 & .00 & .07 & -.13 \\
\hline $\mathrm{FH}^{-}$ & & & - & .20 & -.05 & .05 & .16 & .11 & -.11 & -.09 & -.13 \\
\hline \multirow{2}{*}{\multicolumn{12}{|c|}{$\begin{array}{l}\mathrm{Fn} \\
\mathrm{SKT}\end{array}$}} \\
\hline & & & & & & & & & & & \\
\hline All & & & & - & .08 & -.13 & -.24 & .12 & -.15 & -.12 & -.17 \\
\hline $\mathrm{FH}^{-}$ & & & & - & $.42^{*}$ & -.24 & .06 & .35 & -.35 & -.38 & -.30 \\
\hline $\mathrm{FH}^{+}$ & & & & - & -.09 & -.05 & -.43 & -.06 & .02 & .03 & -.03 \\
\hline
\end{tabular}

Note. $\quad \mathrm{FH}=$ family history of $\mathrm{AD} ; \mathrm{Edu}=$ years of education; $\mathrm{MMSE}=$ Mini Mental State Exam; $\mathrm{SKT}=$ Synonym Knowledge Test; WCST $=$ Wisconsin Card Sorting Test; $\mathrm{CA}=$ Categories Achieved; $\mathrm{TCFC}=$ Trials to Complete First Category; FMS $=$ Failure to Maintain Set; PCLR $=$ Percent Conceptual Level Responses; TE $=$ Total Errors; PE $=$ Perseverative Errors; NPE $=$ Non-Perseverative Errors.

${ }^{*} p<.05 .{ }^{* *} p<.01$

FH group differences on the WCST measures were analyzed first using multivariate analysis of variance (MANOVA), using age and sex as covariates because of the observed correlations. The overall model was not significant for either covariate (age $p=.16$, $\operatorname{sex} p=.19$ ) but was significant for $\mathrm{FH}\left(F(8,31)=2.52, p=.03, \eta_{p}^{2}=.39\right.$, Wilks' $\lambda=$ 0.61). Univariate ANOVA was then performed for each measure. These results are depicted in Figure 1 . There were no significant covariate effects of sex, but significant covariance with age was found for Total Errors, Perseverative Errors, Percent Conceptual Level Responses, and Categories Achieved ( $p s<.01)$. After including these covariates in the model, significant group differences emerged for multiple indices: Categories Achieved, $F(1,38)=15.08, p<.001, \eta_{p}^{2}=.28$; Percent Conceptual Level Responses, $F(1,38)=13.27, p=.001, \eta_{p}^{2}=.26$; Total Errors, $F(1,38)=12.26, p=.001, \eta_{p}^{2}=.24$; Perseverative Errors, $F(1,38)=10.94, p=.002, \eta_{p}^{2}=.22$; and Non-Perseverative Errors, $F(1,38)=5.90, p=.02, \eta_{p}^{2}=.13$. Specifically, those in the $\mathrm{FH}^{+}$group achieved significantly fewer categories, exhibited a significantly lower percentage of Conceptual Level Responses, and committed significantly more errors than those in the $\mathrm{FH}^{-}$group. No significant differences between groups emerged for Trials to Complete First Category, $F(1,38)=1.63, p=.21, \eta_{p}^{2}=.04$, or Failure to Maintain Set, $F(1,38)=0.51, p=.48, \eta_{p}^{2}=.01$.

Neuropsychology, Vol 29, No. 4 (June 2015): pg. 582-591. DOI. This article is (C American Psychological Association and permission has been granted for this version to appear in e-Publications@ Marquette. American Psychological Association does not grant permission for this article to be further copied/distributed or hosted elsewhere without the express permission from American Psychological Association. 
NOT THE PUBLISHED VERSION; this is the author's final, peer-reviewed manuscript. The published version may be accessed by following the link in the citation at the bottom of the page.
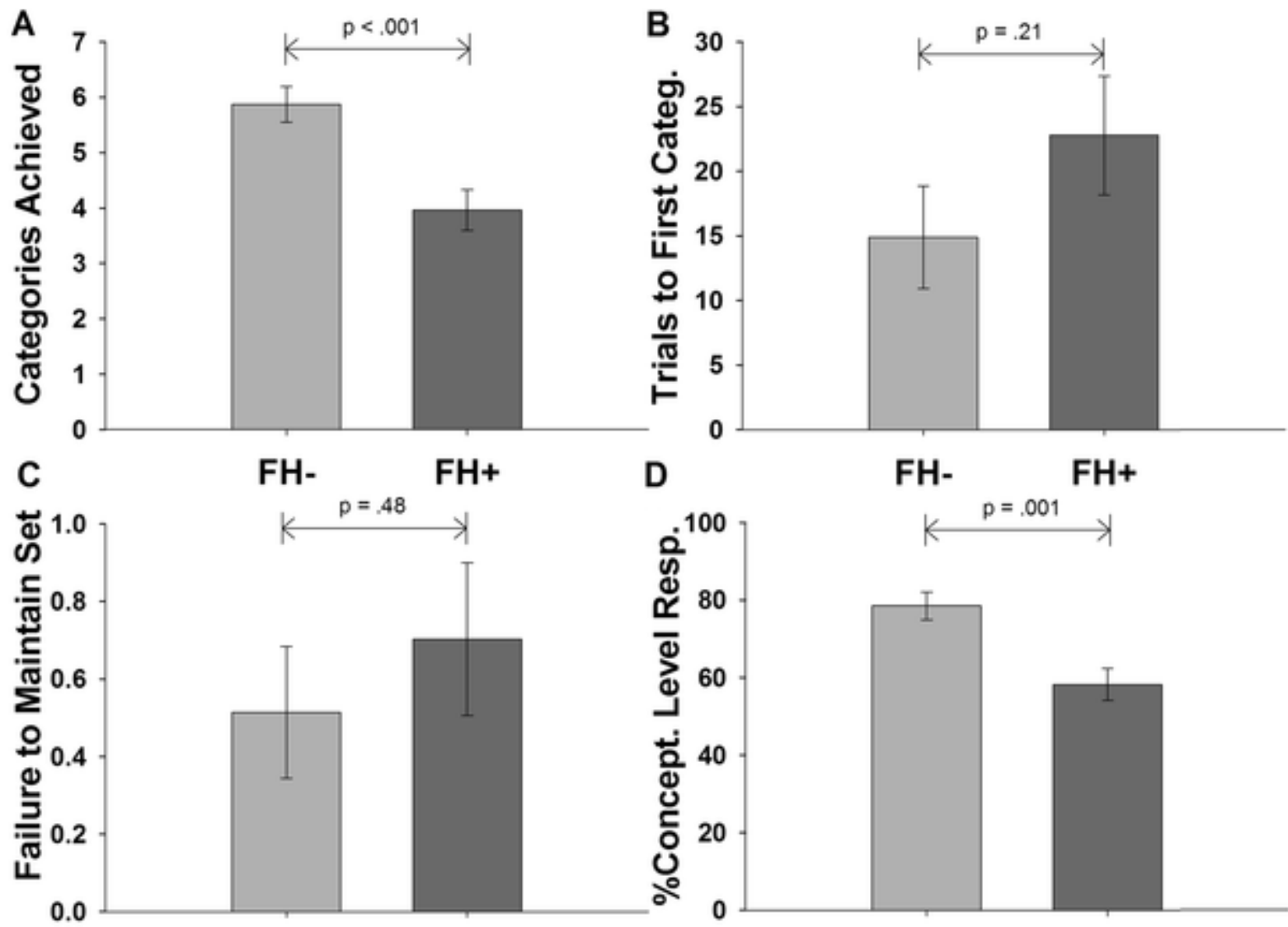

E

FH-

$\mathrm{FH+}$

FH-

$\mathrm{FH}+$

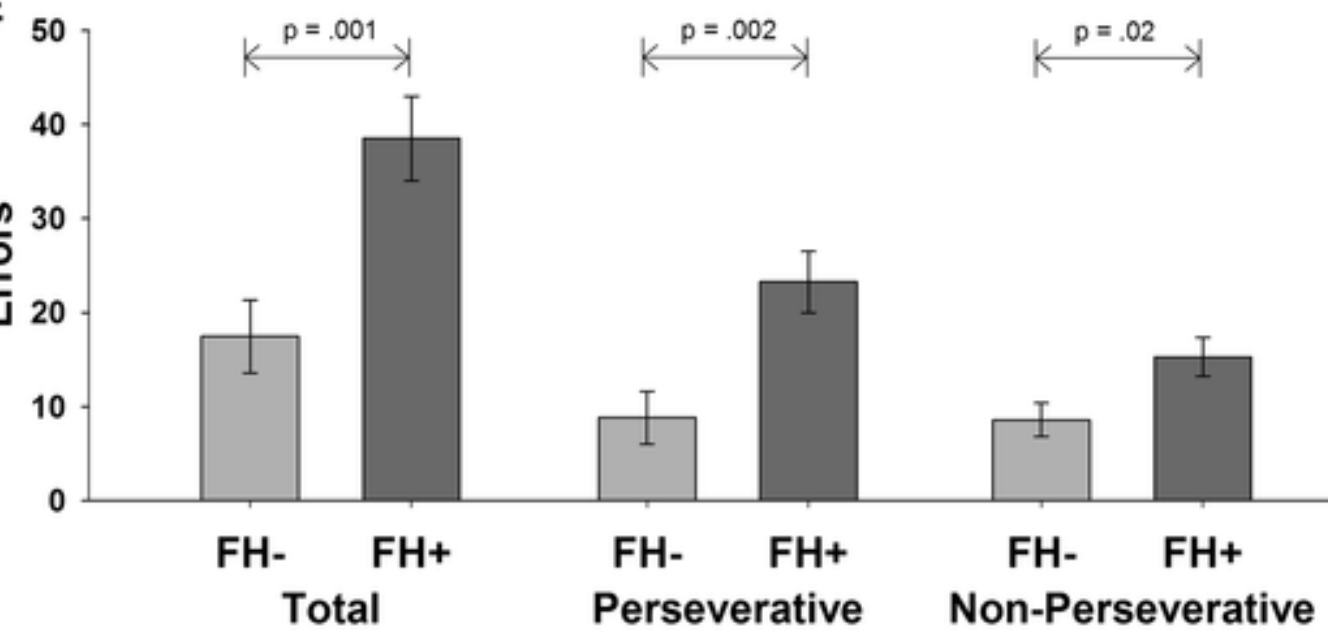

Figure 1. Cognitively intact older adults with a positive family history of $A D$ achieved significantly fewer categories, obtained a lower percentage of conceptual level responses, and committed more errors (total, perseverative, and non-perseverative) than those with no family history of $A D$.

Neuropsychology, Vol 29, No. 4 (June 2015): pg. 582-591. DOl. This article is (C) American Psychological Association and permission has been granted for this version to appear in e-Publications@Marquette. American Psychological Association does not grant permission for this article to be further copied/distributed or hosted elsewhere without the express permission from American Psychological Association. 
To further explore the degree to which $\mathrm{FH}$ predicts performance on the WCST, hierarchical regression analyses were conducted based on the five WCST performance variables for which significant differences emerged between FH risk groups (i.e., Categories Achieved, Percent Conceptual Level Responses, Total Errors, Perseverative Errors, and Non-Perseverative Errors). In each model, age, sex, and education were entered in Step 1 and $\mathrm{FH}$ was added in Step 2. Demographic variables were included in the model because of the significant exploratory correlations with WCST subscores, as well as because previous literature suggests that these variables may play a role in WCST performance (Boone, Ghaffarian, Lesser, Hill-Gutierrez, \& Berman, 1993; Heaton, 1981; Heaton et al., 1993). Given the small sample size and lack of significant correlations for the MMSE and the SKT with the WCST, they were not included in the regressions to help reduce over-fitting the models. Depression and anxiety scores were similarly excluded to prevent over-fitting and because of the extreme score restriction; little depression or anxiety was reported in the sample (see Table 1 ).

Results of the hierarchical regression analyses are presented in Table 3. For each of the five regression analyses, the models failed to reach significance based solely on the demographic variables entered in Step 1. However, when FH was entered in Step 2, all five of the models reached significance. Moreover, although the statistics shown in Table 3 depict a significant contribution of age as a predictor of WCST performance in all models (as well as education, to a modest degree), it is evident that $\mathrm{FH}$ added significantly to each of these predictions, above and beyond the contribution of age alone. Indeed, $\mathrm{FH}$ accounted for more variance in each model than the other three variables combined. 
NOT THE PUBLISHED VERSION; this is the author's final, peer-reviewed manuscript. The published version may be accessed by following the link in the citation at the bottom of the page.

Table 3

Hierarchical Regression Analyses Predicting Performance on the WCST

\begin{tabular}{|c|c|c|c|c|c|c|c|c|c|}
\hline & \multicolumn{4}{|c|}{ Model summary of each step } & \multicolumn{5}{|c|}{ Contribution of each variable in last step } \\
\hline & $\overline{R^{2}}$ & $\Delta R^{2}$ & $F$ & $p$ & B & $S E$ & $\beta$ & $t$ & $p$ \\
\hline \multicolumn{10}{|l|}{ Categories Achieved } \\
\hline Step 1 & .11 & - & 1.57 & .21 & & & & & \\
\hline Age & & & & & -0.08 & 0.03 & -0.41 & -3.08 & .004 \\
\hline Sex & & & & & 0.21 & 0.50 & 0.06 & 0.42 & .68 \\
\hline Edu & & & & & 0.18 & 0.10 & 0.24 & 1.80 & .08 \\
\hline Step 2 & .41 & .29 & 6.29 & .001 & & & & & \\
\hline $\mathrm{FH}$ & & & & & -2.09 & 0.49 & -0.57 & -4.28 & $<.001$ \\
\hline \multirow{2}{*}{\multicolumn{10}{|c|}{$\begin{array}{c}\text { \% Conceptual Level } \\
\text { Responses }\end{array}$}} \\
\hline & & & & & & & & & \\
\hline Age & .10 & - & 2.29 & (W) & -0.96 & 0.28 & -0.46 & -3.46 & .001 \\
\hline Sex & & & & & 3.91 & 5.62 & 0.09 & 0.80 & .49 \\
\hline Edu & & & & & 2.06 & 1.13 & 0.24 & 1.82 & .08 \\
\hline Step 2 & .41 & .26 & 6.51 & $<.001$ & & & & & \\
\hline $\mathrm{FH}$ & & & & & -22.38 & 5.53 & -0.54 & -4.05 & $<.001$ \\
\hline \multirow{2}{*}{\multicolumn{10}{|c|}{$\begin{array}{l}\text { Total Errors } \\
\text { Step } 1\end{array}$}} \\
\hline & & & & & & & & & \\
\hline Age & & & & & 1.08 & 0.30 & 0.47 & 3.57 & .001 \\
\hline Sex & & & & & -3.79 & 6.12 & -0.08 & -0.62 & .54 \\
\hline Edu & & & & & -2.02 & 1.23 & -0.22 & -1.65 & .11 \\
\hline \multicolumn{10}{|l|}{ Step 2} \\
\hline $\mathrm{FH}$ & .40 & .24 & 6.20 & .001 & 23.11 & 6.02 & 0.52 & 3.84 & $<.001$ \\
\hline \multicolumn{10}{|l|}{ Perseverative Errors } \\
\hline Step 1 & .17 & - & 2.72 & .06 & & & & & \\
\hline Age & & & & & 0.81 & 0.23 & 0.49 & 3.61 & .001 \\
\hline Sex & & & & & -2.20 & 4.54 & -0.07 & -0.48 & .63 \\
\hline Edu & & & & & -0.83 & 0.91 & -0.12 & -0.92 & .37 \\
\hline Step 2 & .37 & .20 & 5.53 & .001 & & & & & \\
\hline $\mathrm{FH}$ & & & & & 15.28 & 4.47 & 0.47 & 3.42 & .002 \\
\hline \multicolumn{10}{|l|}{ Non-perseverative Errors } \\
\hline Step 1 & .10 & - & 1.37 & .27 & & & & & \\
\hline Age & & & & & 0.27 & 0.14 & 0.29 & 1.99 & .053 \\
\hline Sex & & & & & -1.50 & 2.73 & -0.08 & -0.55 & .59 \\
\hline Edu & & & & & -1.19 & 0.55 & -0.32 & -2.18 & .04 \\
\hline Step 2 & .27 & .17 & 3.39 & .02 & & & & & \\
\hline $\mathrm{FH}$ & & & & & 7.90 & 2.70 & 0.44 & 2.94 & .006 \\
\hline
\end{tabular}

Note. $\quad \mathrm{Edu}=$ years of education; $\mathrm{FH}=$ family history of $\mathrm{AD}$.

\section{Discussion}

In the present study, healthy, cognitively intact older adults with a family history of AD had significantly poorer scores on the WCST, a classic measure of executive functioning, than comparable elders without a family history of AD. Specifically, those with AD family history completed fewer categories, exhibited a lower percentage of conceptual level responses, and committed more errors. This was despite their normal scores on measures of general cognitive functioning, generally high level of education, and good health. Moreover, hierarchical regression analyses confirmed the role of AD family history in WCST performance. Although greater age predicted poorer performance for each metric, family history also significantly predicted performance. Indeed, the models failed to reach significance with demographic variables alone and family history contributed far more variance to the models. The results are consistent with studies showing that the WCST is sensitive to AD (e.g., Bondi et al., 1993;

Neuropsychology, Vol 29, No. 4 (June 2015): pg. 582-591. DOI. This article is @ American Psychological Association and permission has been granted for this version to appear in e-Publications@Marquette. American Psychological Association does not grant permission for this article to be further copied/distributed or hosted elsewhere without the express permission from American Psychological Association. 
Chao et al., 2013; Nagahama et al., 2003), and extended them to show its sensitivity to risk for AD in cognitively intact elders. The results also complement and extend a recent report showing the sensitivity of a battery of executive measures to $\mathrm{FH}$ in cognitively intact elders (Donix et al., 2012). In the present study, a single test was robustly sensitive to differences by $\mathrm{FH}$.

The number of trials necessary to complete the first set was comparable between the groups. However, conceptual level responding was poorer in the $\mathrm{FH}^{+}$group. This is indicative of poor insight into the correct sorting strategy, which is necessary for accurate shifting of set when the sorting principle changes. The greater number of errors and fewer number of categories completed in the $\mathrm{FH}^{+}$group are also consistent with poorer insight into the sorting strategy. Increased perseveration in older adults has previously been linked to such set-shifting difficulties (Ridderinkhof, Span, \& van der Molen, 2002). Additionally, evidence from the Stroop test, another commonly used EF measure, indicates set-shifting impairment among those with $A D$, because of difficulty suppressing previously relevant rules and learning new rules across multiple variations of the Stoop test (Amieva et al., 2004a). Similar, albeit less severe, difficulties were evident in the cognitively intact $\mathrm{FH}^{+}$participants in the current study.

Failures of maintaining set were also comparable between groups. Thus, once the set was achieved, it appears that both groups were able to maintain it. However, closer consideration of the WCST suggests an alternative explanation. Although $\mathrm{FH}^{-}$participants exhibited few set maintenance failures because of accurate category completion, $\mathrm{FH}^{+}$participants obtained too few consecutively correct responses (i.e., five or more are required) to meet the criteria for a "Failure to Maintain Set" when an error occurred. That is, one must accurately change set, maintain the new set for five or more trials, and subsequently lose set to commit a Failure. Thus, set-shifting difficulties in the $\mathrm{FH}^{+}$group prevented them from accurately changing set in the first place. Further confirmation of this is shown in their higher error rates and poorer conceptual level responding, rather than difficulty maintaining set.

Our findings, in conjunction with findings regarding the sensitivity of the WCST in detecting AD (Bondi et al., 1993; Chao et

Neuropsychology, Vol 29, No. 4 (June 2015): pg. 582-591. DOI. This article is (C American Psychological Association and permission has been granted for this version to appear in e-Publications@Marquette. American Psychological Association does not grant permission for this article to be further copied/distributed or hosted elsewhere without the express permission from American Psychological Association. 
al., 2013; Nagahama et al., 2003), speak to the importance of examining cognitive domains other than memory to better understand risk for and manifestation of $A D$. Executive functioning is one domain recognized by the National Institute on Aging and the Alzheimer's Association in their recent diagnostic recommendations, which include a classification for nonamnestic AD specifically characterized by executive dysfunction (McKhann et al., 2011). The executive abilities necessary for successful completion of the WCST (e.g., sustained attention, set shifting, inhibition, and planning) are similar to those required for daily functioning and WCST performance has been linked to the ability to complete activities of daily living (Jefferson et al., 2006; Martyr \& Clare, 2012). Despite the empirical focus on memory deficits in $A D$, these executive processes are also affected by $A D$. Deficits in this domain are, in fact, among the first nonmemory impairments to emerge with AD onset (Amieva, Phillips, Della Sala, \& Henry, 2004b). Moreover, these executive deficits may be related to, or even underlie, certain aspects of memory decline (Baudic et al., 2006; Gleichgerrcht et al., 2011; Hasher et al., 2007). Further research elucidating the role of $E F$ in risk for $A D$ is, therefore, necessary. As research within this domain progresses, however, it will be important to more fully examine the unique and shared contributions of these executive abilities and memory in determining risk for AD. Indeed, previous findings suggest co-occurring and agerelated neural network changes underlying both EF and memory (Buckner, 2004). However, evidence also supports dissociation of these networks (Buckner, 2004). Future work assessing EF and memory in the same study, as well as their neural underpinnings, will be important for understanding the independent risk each domain confers to AD development. This may be particularly important and impactful at early stages of disease progression. The assessment of executive functioning in those at risk for $A D$, but at a stage before clinically acknowledged disease onset, is imperative for broadening the current literature and the clinical utility of such commonly used executive functioning measures.

Given the importance of assessing risk for AD early in the course of disease progression and ideally before disease onset, the examination of cognitively intact older adults was the focus of the present study. The most commonly used cutoff for the MMSE to define intact cognitive functioning is 24 (Lopez, Charter, Mostafavi, Nibut, \& permission has been granted for this version to appear in e-Publications@Marquette. American Psychological Association does not grant permission for this article to be further copied/distributed or hosted elsewhere without the express permission from American Psychological Association. 
Smith, 2005; Mitchell, 2009; Tombaugh \& Mcintyre, 1992). However, the use of a cut-off score of 27 has recently been emphasized to improve sensitivity and specificity in highly educated White examinees (e.g., O'Bryant et al., 2008). The four participants in the present study who scored below 27 all obtained a score of 26, principally because of poor performance on the Serial $7 \mathrm{~s}$ Attention item. This pattern of difficulty is consistent with previous research describing early decline with advancing age for this item (e.g., Ishizaki et al., 1998). Although the alternate item (WORLD backward) is considered easier (e.g., Ganguli et al., 1990) and is often administered and scored instead when poor performance results on Serial 7s (e.g., Crum, Anthony, Bassett, \& Folstein, 1993), this procedure was not used in the present study. Thus, it is likely that all our participants would have achieved at least 27 had that procedure been used. Regardless, such attention to cutoff ranges on the MMSE is likely not very meaningful given the blunt nature of the instrument (cf. Lopez et al., 2005). Moreover, all four of the participants with scores of 26 were in the $\mathrm{FH}^{-}$group (the better performers on the WCST), which alleviates concern about the contribution of poor general cognitive performance to the pattern of the present results. As confirmation of that conclusion, we removed these four participants from the analysis, but the pattern of results was unchanged.

This study was not without limitations. First, the study sample was rather small and thus it is unclear whether these findings would generalize to a larger, and potentially more diverse, group. However, very robust effects of AD family history on WCST performance were evident even in a sample of this size. Given the small group sizes, statistical analyses based on specific familial relationship of AD family history (e.g., parent vs. sibling, maternal vs. paternal) could not be conducted in the present study. However, the strong criteria for $\mathrm{FH}$ (i.e., first-degree relative required) and the high rate of $\mathrm{FH}$ originating from the maternal side, which tends to convey greater risk (e.g., Johnson et al., 2014; Reiter et al., 2012), may have helped to strengthen the findings. Second, family history was determined by participant report. Confirmation of diagnosis was not available through medical records or autopsy confirmation. Furthermore, although sex correlated with WCST performance in the $\mathrm{FH}^{-}$group, the relatively small number of males in the sample precluded a thorough investigation of these relationships. Additional research with a larger,

Neuropsychology, Vol 29, No. 4 (June 2015): pg. 582-591. DOI. This article is (C) American Psychological Association and permission has been granted for this version to appear in e-Publications@Marquette. American Psychological Association does not grant permission for this article to be further copied/distributed or hosted elsewhere without the express permission from American Psychological Association. 
more balanced sample would be helpful in clarifying the role of sex in WCST performance and evaluating whether it interacts with other predictors such as age and AD family history.

The differences in the present study attributable to family history risk for AD signal an inherited factor that affects executive functioning. Assessment of $\mathrm{FH}$ is extremely cost-effective and noninvasive, making it a very efficient method of assessing risk. Moreover, recent reports suggest that the cognitive and cortical differences associated with $\mathrm{FH}$ are separable from at least some known genetic risks for AD (e.g., La Rue et al., 2008; Reiter et al., 2012), signaling that $\mathrm{FH}$ may represent an as of yet unknown factor that can modulate the effects of such genes (e.g., Bendlin et al., 2010; Johnson et al., 2006; Xu et al., 2009). Nonetheless, the more precise basis of inherited risk cannot be discerned by family history assessment alone. Future investigation of the genetic and other lifestyle contributions (e.g., nutrition, socioeconomic status, etc.) to this effect would be important. Although there are multiple hereditary factors associated with $A D$, the apolipoprotein-E (APOE) $\varepsilon 4$ allele is a well-recognized, important risk factor for $A D$ that is also associated with familial clustering (e.g., Saunders et al., 1993a, 1993b). Furthermore, its presence has been associated with differential brain activity patterns, including in the frontal lobes, in studies with cognitively intact elders (e.g., Hantke et al., 2013; Seidenberg et al., 2013; Smith et al., 2014) and the literature as a whole supports a robust negative effect of APOE $\varepsilon 4$ on multiple domains of cognition in healthy elders, including executive functioning (Wisdom, Callahan, \& Hawkins, 2011).

The distribution of APOE $\varepsilon 4$ allele in our sample is not known, but differential performance on the WCST could be because of APOE $\varepsilon 4$ inheritance. One study supporting this idea (Wetter et al., 2005) showed that $\varepsilon 4$ carriers differed from noncarriers on the DKEFS ColorWord Interference Test (Delis, Kaplan, \& Kramer, 2001), a task similar to the Stroop (1935) test, specifically on an inhibition/switching condition that may tap skills comparable with those required by the WCST. In contrast, other studies found no general difference on the WCST in cognitively intact elders by $\varepsilon 4$ (Caselli, Reiman, Hentz, Osborne, \& Alexander, 2004; Etnier et al., 2007), although in one (Caselli et al., 2004) there were interactive effects where $\varepsilon 4$ noncarriers with high trait anxiety outperformed high-anxiety $\varepsilon 4$

Neuropsychology, Vol 29, No. 4 (June 2015): pg. 582-591. DOI. This article is (C American Psychological Association and permission has been granted for this version to appear in e-Publications@ Marquette. American Psychological Association does not grant permission for this article to be further copied/distributed or hosted elsewhere without the express permission from American Psychological Association. 
homozygotes, carriers of the highest risk allele combination that occurs in only about $2 \%$ of the general population (e.g., Mahley, 1988; Saunders et al., 1993b); no differences existed for $\varepsilon 4$ heterozygotes. Although the current study cannot directly address APOE $\varepsilon 4$ or trait anxiety findings, it notably supports robust effects of AD family history on WCST performance in healthy elders, which is not yet matched by studies using APOE $\varepsilon 4$ as the measure of risk. Moreover, recent studies report FH effects on cognitive (Donix et al., 2012; La Rue et al., 2008) and cortical changes with age (Reiter et al., 2012) that are distinct from APOE $\varepsilon 4$ contributions, and some suggest that $\mathrm{FH}$ may modulate the effect of $\varepsilon 4$, suggesting that a different factor underlying $\mathrm{FH}$ influences the expression of APOE $\varepsilon 4$ on neural structure (Bendlin et al., 2010) and functioning (Johnson et al., 2006; Xu et al., 2009). Additionally, Donix and colleagues (2012) reported that although cognitively intact elders had poorer executive functioning than their lower risk counterparts, FH did not contribute to decline over time, whereas APOE $\varepsilon 4$ did. The current study did not investigate change over time. Thus, there is yet need for much investigation into the effects of AD family history on cognitive aging separately from and in conjunction with known genetic risks such as APOE $\varepsilon 4$. A longitudinal approach to such investigations would be particularly beneficial for identifying predictors of cognitive decline and disease progression. Our study suggests these investigations should specifically target executive functioning, likely using multiple executive tasks (including WCST) within the same sample, to elucidate the nuanced characteristics of the various aspects of EF that are and are not subject to early stage vulnerability to AD risk factors.

In conclusion, this study demonstrated that family history of AD was significantly associated with poorer executive functioning performance on the traditional WCST among cognitively intact elders. These findings expand the literature regarding executive functioning abilities as they relate to aging and risk for $A D$, highlighting the need to examine cognitive domains beyond memory. These results underscore the importance of considering executive abilities as part of the exploration of potential early markers of future cognitive decline. 
NOT THE PUBLISHED VERSION; this is the author's final, peer-reviewed manuscript. The published version may be accessed by following the link in the citation at the bottom of the page.

\section{Footnotes}

${ }^{1}$ Note that education was not included as a covariate because of the sample size and its overall lack of correlation with the outcome variables. However, when included, it did not serve as a significant covariate in the overall model or for Failure to Maintain Set.

\section{References}

Alzheimer's Association. (2012). 2012 Alzheimer's disease facts and figures. Alzheimer's \& Dementia, 8, 131-168. 10.1016/j.jalz.2012.02.001

Alzheimer's Association. (2013). 2013 Alzheimer's disease facts and figures. Alzheimer's \& Dementia, 9, 208-245. 10.1016/j.jalz.2013.02.003

Amieva, H., Lafont, S., Rouch-Leroyer, I., Rainville, C., Dartigues, J. F., Orgogozo, J. M., \& Fabrigoule, C. (2004a). Evidencing inhibitory deficits in Alzheimer's disease through interference effects and shifting disabilities in the Stroop test. Archives of Clinical Neuropsychology, 19, 791-803. 10.1016/j.acn.2003.09.006

Amieva, H., Phillips, L. H., Della Sala, S., \& Henry, J. D. (2004b). Inhibitory functioning in Alzheimer's disease. Brain: A Journal of Neurology, 127, 949-964. 10.1093/brain/awh045

Andersen, C. K., Wittrup-Jensen, K. U., Lolk, A., Andersen, K., \& KraghSørensen, P. (2004). Ability to perform activities of daily living is the main factor affecting quality of life in patients with dementia. Health and Quality of Life Outcomes, 2, 52. 10.1186/1477-7525-2-52

Baudic, S., Barba, G. D., Thibaudet, M. C., Smagghe, A., Remy, P., \& Traykov, L. (2006). Executive function deficits in early Alzheimer's disease and their relations with episodic memory. Archives of Clinical Neuropsychology, 21, 15-21. 10.1016/j.acn.2005.07.002

Beck, A. T., \& Steer, R. A. (1993). Beck Anxiety Inventory Manual. San Antonio, TX: Harcourt Brace and Company.

Beck, A. T., Steer, R. A., \& Brown, G. K. (1996). Manual for the Beck Depression Inventory-II. San Antonio, TX: Psychological Corporation.

Bendlin, B. B., Ries, M. L., Canu, E., Sodhi, A., Lazar, M., Alexander, A. L., . . Johnson, S. C. (2010). White matter is altered with parental family history of Alzheimer's disease. Alzheimer's \& Dementia, 6, 394403. 10.1016/j.jalz.2009.11.003

Bondi, M. W., Monsch, A. U., Butters, N., Salmon, D. P., \& Paulsen, J. S. (1993). Utility of a modified version of the Wisconsin Card Sorting Test in the detection of dementia of the Alzheimer type. Clinical Neuropsychologist, 7, 161-170. 10.1080/13854049308401518

Boone, K. B., Ghaffarian, S., Lesser, I. M., Hill-Gutierrez, E., \& Berman, N. G. (1993). Wisconsin Card Sorting Test performance in healthy, older

Neuropsychology, Vol 29, No. 4 (June 2015): pg. 582-591. DOI. This article is (C American Psychological Association and permission has been granted for this version to appear in e-Publications@Marquette. American Psychological Association does not grant permission for this article to be further copied/distributed or hosted elsewhere without the express permission from American Psychological Association. 
adults: Relationship to age, sex, education, and IQ. Journal of Clinical Psychology, 49, 54-60. 10.1002/1097-4679(199301)49:1<54::AIDJCLP2270490108>3.0.CO;2-6

Buckner, R. L. (2004). Memory and executive function in aging and AD: Multiple factors that cause decline and reserve factors that compensate. Neuron, 44,195-208.10.1016/j.neuron.2004.09.006

Caselli, R. J., Reiman, E. M., Hentz, J. G., Osborne, D., \& Alexander, G. E. (2004). A distinctive interaction between chronic anxiety and problem solving in asymptomatic APOE e4 homozygotes. The Journal of Neuropsychiatry and Clinical Neurosciences, 16, 320-329. 10.1176/appi.neuropsych.16.3.320

Chao, J., Hao, L., Chao, I., Shi, M., \& Chao, I. (2013). Utility of Nelson's modified card sorting test in patients with Alzheimer's disease or vascular dementia. Open Journal of Preventive Medicine, 3, 172-177. 10.4236/ojpm.2013.32023

Clark, L. R., Stricker, N. H., Libon, D. J., Delano-Wood, L., Salmon, D. P., Delis, D. C., \& Bondi, M. W. (2012). Yes/no versus forced-choice recognition memory in mild cognitive impairment and Alzheimer's disease: Patterns of impairment and associations with dementia severity. The Clinical Neuropsychologist, 26, 1201-1216. 10.1080/13854046.2012.728626

Creed, P. A., \& Wiener, K. K. (1999). Use of the Shipley Institute of Living Scale and the Raven's Standard Progressive Matrices with unemployed populations. Journal of Applied Health Behaviour, 1, 22-26.

Crum, R. M., Anthony, J. C., Bassett, S. S., \& Folstein, M. F. (1993). Population-based norms for the Mini-Mental State Examination by age and educational level. Journal of the American Medical Association, 269, 2386-2391. 10.1001/jama.1993.03500180078038

Daniels, K., Toth, J., \& Jacoby, L. (2006). The aging of executive functions. In E.Bialystok \& F. I. M.Craik (Eds.), Lifespan cognition (pp. 96-111). New York, NY: Oxford University Press.

Delis, D. C., Kaplan, E., \& Kramer, J. H. (2001). Delis-Kaplan Executive Function System (D-KEFS). San Antonio, TX: The Psychological Corporation.

Donix, M., Ercoli, L. M., Siddarth, P., Brown, J. A., Martin-Harris, L., Burggren, A. C., . . Bookheimer, S. Y. (2012). Influence of Alzheimer disease family history and genetic risk on cognitive performance in healthy middle-aged and older people. The American Journal of Geriatric Psychiatry, 20, 565-573. 10.1097/JGP.0b013e3182107e6a

Duarte, A., Hayasaka, S., Du, A., Schuff, N., Jahng, G.-H., Kramer, J., . . .Weiner, M. (2006). Volumetric correlates of memory and executive function in normal elderly, mild cognitive impairment and

Neuropsychology, Vol 29, No. 4 (June 2015): pg. 582-591. DOI. This article is (C American Psychological Association and permission has been granted for this version to appear in e-Publications@Marquette. American Psychological Association does not grant permission for this article to be further copied/distributed or hosted elsewhere without the express permission from American Psychological Association. 
NOT THE PUBLISHED VERSION; this is the author's final, peer-reviewed manuscript. The published version may be accessed by following the link in the citation at the bottom of the page.

Alzheimer's disease. Neuroscience Letters, 406, 60-65. 10.1016/j.neulet.2006.07.029

Eling, P., Derckx, K., \& Maes, R. (2008). On the historical and conceptual background of the Wisconsin Card Sorting Test. Brain and Cognition, 67, 247-253. 10.1016/j.bandc.2008.01.006

Elliott, R. (2003). Executive functions and their disorders. British Medical Bulletin, 65, 49-59. 10.1093/bmb/65.1.49

Espinosa, A., Alegret, M., Boada, M., Vinyes, G., Valero, S., Martínez-Lage, P., . . Tárraga, L. (2009). Ecological assessment of executive functions in mild cognitive impairment and mild Alzheimer's disease. Journal of the International Neuropsychological Society, 15, 751-757. 10.1017/S135561770999035X

Etnier, J. L., Caselli, R. J., Reiman, E. M., Alexander, G. E., Sibley, B. A., Tessier, D., \& McLemore, E. C. (2007). Cognitive performance in older women relative to ApoE-epsilon4 genotype and aerobic fitness.

Medicine and Science in Sports and Exercise, 39, 199-207. 10.1249/01.mss.0000239399.85955.5e

Folstein, M. F., Folstein, S. E., \& McHugh, P. R. (1975). "Mini-mental state". A practical method for grading the cognitive state of patients for the clinician. Journal of Psychiatric Research, 12, 189-198. 10.1016/00223956(75)90026-6

Ganguli, M., Ratcliff, G., Huff, F. J., Belle, S., Kancel, M. J., Fischer, L., \& Kuller, L. H. (1990). Serial sevens versus world backwards: A comparison of the two measures of attention from the MMSE. Journal of Geriatric Psychiatry and Neurology, 3, 203-207. 10.1177/089198879000300405

Gleichgerrcht, E., Torralva, T., Martinez, D., Roca, M., \& Manes, F. (2011). Impact of executive dysfunction on verbal memory performance in patients with Alzheimer's disease. Journal of Alzheimer's Disease, 23, 79-85.

Grant, D. A., \& Berg, E. A. (1948). A behavioral analysis of degree of reinforcement and ease of shifting to new responses in a Weigl-type card-sorting problem. Journal of Experimental Psychology, 38, 404411. 10.1037/h0059831

Hantke, N., Nielson, K. A., Woodard, J. L., Breting, L. M., Butts, A., Seidenberg, M., . . .Rao, S. M. (2013). Comparison of semantic and episodic memory BOLD fMRI activation in predicting cognitive decline in older adults. Journal of the International Neuropsychological Society, 19, 11-21. 10.1017/S1355617712000951

Hasher, L., Lustig, C., \& Zacks, R. (2007). Inhibitory mechanisms and the control of attention. In A. R. A.Conway, C.Jarrold, M. J.Kane, \& J. N.Towse (Eds.), Variation in working memory (pp. 227-249). New York, NY: Oxford University Press.

Neuropsychology, Vol 29, No. 4 (June 2015): pg. 582-591. DOI. This article is (C American Psychological Association and permission has been granted for this version to appear in e-Publications@ Marquette. American Psychological Association does not grant permission for this article to be further copied/distributed or hosted elsewhere without the express permission from American Psychological Association. 
Heaton, R. K. (1981). A manual for the Wisconsin Card Sorting Test. Odessa, FL: Psychological Assessment Resources.

Heaton, R. K., Chelune, G. J., Talley, J. L., Kay, G. G., \& Curtis, G. (1993). Wisconsin Card Sorting Test manual: Revised and expanded. Odessa, FL: Psychological Assessment Resources.

Ishizaki, J., Meguro, K., Ambo, H., Shimada, M., Yamaguchi, S., Hayasaka, C., . . .Yamadori, A. (1998). A normative, community-based study of Mini-Mental State in elderly adults: The effect of age and educational level. The Journals of Gerontology Series B: Psychological Sciences and Social Sciences, 53B, P359-P363. 10.1093/geronb/53B.6.P359

Jefferson, A. L., Paul, R. H., Ozonoff, A., \& Cohen, R. A. (2006). Evaluating elements of executive functioning as predictors of instrumental activities of daily living (IADLs). Archives of Clinical Neuropsychology, 21, 311-320. 10.1016/j.acn.2006.03.007

Johnson, S. C., Christian, B. T., Okonkwo, O. C., OH, J. M., Harding, S., Xu, G., . . Sager, M. A. (2014). Amyloid burden and neural function in people at risk for Alzheimer's Disease. Neurobiology of Aging, 35, 576584. 10.1016/j.neurobiolaging.2013.09.028

Johnson, S. C., Schmitz, T. W., Trivedi, M. A., Ries, M. L., Torgerson, B. M., Carlsson, C. M., . . .Sager, M. A. (2006). The influence of Alzheimer disease family history and apolipoprotein $E$ \&4 on mesial temporal lobe activation. The Journal of Neuroscience, 26, 6069-6076. 10.1523/JNEUROSCI.0959-06.2006

Langenecker, S. A., Zubieta, J. K., Young, E. A., Akil, H., \& Nielson, K. A. (2007). A task to manipulate attentional load, set-shifting, and inhibitory control: Convergent validity and test-retest reliability of the Parametric Go/No-Go Test. Journal of Clinical and Experimental Neuropsychology, 29, 842-853. 10.1080/13803390601147611

La Rue, A., Hermann, B., Jones, J. E., Johnson, S., Asthana, S., \& Sager, M. A. (2008). Effect of parental family history of Alzheimer's disease on serial position profiles. Alzheimer's \& Dementia, 4, 285-290. 10.1016/j.jalz.2008.03.009

Lopez, M. N., Charter, R. A., Mostafavi, B., Nibut, L. P., \& Smith, W. E. (2005). Psychometric properties of the Folstein Mini-Mental State Examination. Assessment, 12, 137-144. 10.1177/1073191105275412

Mahley, R. W. (1988). Apolipoprotein E: Cholesterol transport protein with expanding role in cell biology. Science, 240, 622-630. $10.1126 /$ science. 3283935

Martyr, A., \& Clare, L. (2012). Executive function and activities of daily living in Alzheimer's disease: A correlational meta-analysis. Dementia and Geriatric Cognitive Disorders, 33, 189-203. 10.1159/000338233

Neuropsychology, Vol 29, No. 4 (June 2015): pg. 582-591. DOI. This article is (C American Psychological Association and permission has been granted for this version to appear in e-Publications@ Marquette. American Psychological Association does not grant permission for this article to be further copied/distributed or hosted elsewhere without the express permission from American Psychological Association. 
McGuinness, B., Barrett, S. L., Craig, D., Lawson, J., \& Passmore, A. P. (2010). Executive functioning in Alzheimer's disease and vascular dementia. International Journal of Geriatric Psychiatry, 25, 562-568.

McKhann, G. M., Knopman, D. S., Chertkow, H., Hyman, B. T., Jack, C. R., Jr., Kawas, C. H., . . .Phelps, C. H. (2011). The diagnosis of dementia due to Alzheimer's disease: Recommendations from the National Institute on Aging-Alzheimer's Association workgroups on diagnostic guidelines for Alzheimer's disease. Alzheimer's \& Dementia, 7, 263269. 10.1016/j.jalz.2011.03.005

Mitchell, A. J. (2009). A meta-analysis of the accuracy of the mini-mental state examination in the detection of dementia and mild cognitive impairment. Journal of Psychiatric Research, 43, 411-431. 10.1016/j.jpsychires.2008.04.014

Miyake, A., Friedman, N. P., Emerson, M. J., Witzki, A. H., Howerter, A., \& Wager, T. D. (2000). The unity and diversity of executive functions and their contributions to complex "Frontal Lobe" tasks: A latent variable analysis. Cognitive Psychology, 41, 49-100.

10.1006/cogp.1999.0734

Mosconi, L., Berti, V., Swerdlow, R. H., Pupi, A., Duara, R., \& de Leon, M. (2010). Maternal transmission of Alzheimer's disease: Prodromal metabolic phenotype and the search for genes. Human Genomics, 4, 170-193. 10.1186/1479-7364-4-3-170

Nagahama, Y., Okina, T., Suzuki, N., Matsuzaki, S., Yamauchi, H., Nabatame, H., \& Matsuda, M. (2003). Factor structure of a modified version of the Wisconsin card sorting test: An analysis of executive deficit in Alzheimer's disease and mild cognitive impairment. Dementia and Geriatric Cognitive Disorders, 16, 103-112. 10.1159/000070683

Nelson, H. E. (1976). A modified card sorting test sensitive to frontal lobe defects. Cortex, 12, 313-324. 10.1016/S0010-9452(76)80035-4

O'Bryant, S. E., Humphreys, J. D., Smith, G. E., Ivnik, R. J., Graff-Radford, N. R., Petersen, R. C., \& Lucas, J. A. (2008). Detecting dementia with the mini-mental state examination in highly educated individuals. Archives of Neurology, 65, 963-967.

Reiter, K., Alpert, K. I., Cobia, D. J., Kwasny, M. J., Morris, J. C., Csernansky, J. C., \& Wang, L. (2012). Cognitively normal individuals with AD parents may be at risk for developing aging-related cortical thinning patterns characteristic of AD. NeuroImage, 61, 525-532. 10.1016/j.neuroimage.2012.03.083

Ridderinkhof, K. R., Span, M. M., \& van der Molen, M. W. (2002). Perseverative behavior and adaptive control in older adults: Performance monitoring, rule induction, and set shifting. Brain and Cognition, 49, 382-401. 10.1006/brcg.2001.1506

Neuropsychology, Vol 29, No. 4 (June 2015): pg. 582-591. DOI. This article is (C American Psychological Association and permission has been granted for this version to appear in e-Publications@ Marquette. American Psychological Association does not grant permission for this article to be further copied/distributed or hosted elsewhere without the express permission from American Psychological Association. 
Salmon, D. P., \& Bondi, M. W. (2009). Neuropsychological assessment of dementia. Annual Review of Psychology, 60, 257-282.

10.1146/annurev.psych.57.102904.190024

Saunders, A. M., Roses, A. D., Pericak-Vance, M. A., Dole, K. C., Strittmatter, W. J., Schmechel, D. E., . . .Brown, W. T. (1993a). Apolipoprotein E ع4 allele distributions in late-onset Alzheimer's disease and in other amyloid-forming diseases. Lancet, 342, 710-711. 10.1016/01406736(93)91709-U

Saunders, A. M., Strittmatter, W. J., Schmechel, D., George-Hyslop, P. H., Pericak-Vance, M. A., Joo, S. H., . . .Roses, A. D. (1993b). Association of apolipoprotein $\mathrm{E}$ allele $\varepsilon 4$ with late-onset familial and sporadic Alzheimer's disease. Neurology, 43, 1467-1472. 10.1212/WNL.43.8.1467

Seidenberg, M., Kay, C. D., Woodard, J. L., Nielson, K. A., Smith, J. C., Kandah, C., . . .Rao, S. M. (2013). Recognition of famous names predicts cognitive decline in healthy elders. Neuropsychology, 27, 333342. $10.1037 / \mathrm{a} 0032226$

Shipley, W. C. (1946). Institute of Living Scale. Los Angeles, CA: Western Psychological Services.

Silverman, J. M., Raiford, K., Edland, S., Fillenbaum, G., Morris, J. C., Clark, C. M., . . .Heyman, A. (1994). The Consortium to Establish a Registry for Alzheimer's Disease (CERAD). Part VI. Family history assessment: A multicenter study of first-degree relatives of Alzheimer's disease probands and nondemented spouse controls. Neurology, 44, 12531259. 10.1212/WNL.44.7.1253

Smith, J. C., Nielson, K. A., Woodard, J. L., Seidenberg, M., Durgerian, S., Hazlett, K. E., . . .Rao, S. M. (2014). Physical activity reduces hippocampal atrophy in elders at genetic risk for Alzheimer's disease. [Advance online publication]. Frontiers in Aging Neuroscience, 6, 61. 10.3389/fnagi.2014.00061

Sperling, R. A., Aisen, P. S., Beckett, L. A., Bennett, D. A., Craft, S., Fagan, A. M., . . .Phelps, C. H. (2011). Toward defining the preclinical stages of Alzheimer's disease: Recommendations from the National Institute on Aging-Alzheimer's Association workgroups on diagnostic guidelines for Alzheimer's disease. Alzheimer's \& Dementia, 7, 280-292. 10.1016/j.jalz.2011.03.003

Stokholm, J., Vogel, A., Gade, A., \& Waldemar, G. (2006). Heterogeneity in executive impairment in patients with very mild Alzheimer's disease. Dementia and Geriatric Cognitive Disorders, 22, 54-59. $10.1159 / 000093262$

Stroop, J. R. (1935). Studies of interference in serial verbal reactions. Journal of Experimental Psychology, 18, 643-662. 10.1037/h0054651

Neuropsychology, Vol 29, No. 4 (June 2015): pg. 582-591. DOI. This article is (C American Psychological Association and permission has been granted for this version to appear in e-Publications@Marquette. American Psychological Association does not grant permission for this article to be further copied/distributed or hosted elsewhere without the express permission from American Psychological Association. 
Takeda, N., Terada, S., Sato, S., Honda, H., Yoshida, H., Kishimoto, Y., . . . Kuroda, S. (2010). Wisconsin card sorting test and brain perfusion imaging in early dementia. Dementia and Geriatric Cognitive Disorders, 29, 21-27. 10.1159/000261645

Tombaugh, T. N., \& McIntyre, N. J. (1992). The mini-mental state examination: A comprehensive review. Journal of the American Geriatrics Society, 40, 922-935.

Wetter, S. R., Delis, D. C., Houston, W. S., Jacobson, M. W., Lansing, A., Cobell, K., ... Bondi, M. W. (2005). Deficits in inhibition and flexibility are associated with the APOE-E4 allele in nondemented older adults. Journal of Clinical and Experimental Neuropsychology, 27, 943-952. 10.1080/13803390490919001

Wisdom, N. M., Callahan, J. L., \& Hawkins, K. A. (2011). The effects of apolipoprotein $\mathrm{E}$ on non-impaired cognitive functioning: A metaanalysis. Neurobiology of Aging, 32, 63-74. 10.1016/j.neurobiolaging.2009.02.003

Xu, G., McLaren, D. G., Ries, M. L., Fitzgerald, M. E., Bendlin, B. B., Rowley, H. A., . . .Johnson, S. C. (2009). The influence of parental history of Alzheimer's disease and apolipoprotein $\mathrm{E} \varepsilon 4$ on the BOLD signal during recognition memory. Brain: A Journal of Neurology, 132(Pt 2), 383391. 10.1093/brain/awn254 